\title{
Erratum to: Travelling wave analysis in chemotaxis: case of starvation
}

\author{
P. M. Tchepmo Djomegni ${ }^{1,2^{*}}$ and Keshlan Sathasiva Govinder ${ }^{2}$
}

\section{Erratum to: SpringerPlus (2016) 5:917 DOI 10.1186/s40064-016-2507-8}

Upon publication of the original manuscript (Tchepmo Djomegni 2016), the author noticed that he had confused the manuscript with an extension version in which he is the sole author. Prof. Kesh Govinder also contributed to this manuscript, as the work was conducted under his supervision at the University of KwaZulu-Natal, which should be added as both authors' affiliated institutions. Prof. Kesh Govinder has therefore been added as an author to this manuscript, and the affiliations updated, by means of this erratum.

Furthermore, the authors have amended the below statements:

New Competing interests statement: Both authors declare that they have no competing interests.

New Authors' contribution statement: Both authors have contributed equally to the manuscript.

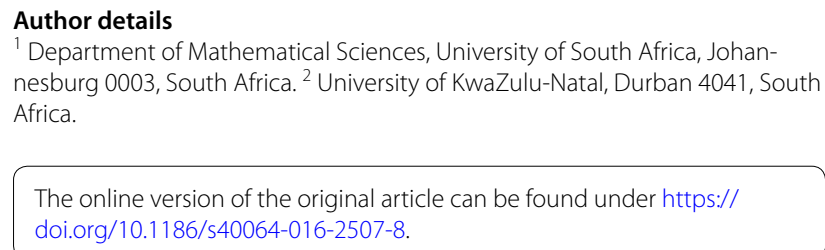

${ }_{1}^{1}$ Department of Mathematical Sciences, University of South Africa, Johannesburg 0003, South Africa. ${ }^{2}$ University of KwaZulu-Natal, Durban 4041, South Africa.

The online version of the original article can be found under https:// doi.org/10.1186/s40064-016-2507-8.

\section{Publisher's Note}

Springer Nature remains neutral with regard to jurisdictional claims in published maps and institutional affiliations.

Received: 21 June 2017 Accepted: 21 June 2017 Published online: 05 February 2018

\section{Reference}

Tchepmo Djomegni PM (2016) Travelling wave analysis in chemotaxis: case of starvation. SpringerPlus 5:917. https://doi.org/10.1186/ s40064-016-2507-8 